\title{
Evaluation of the vacuum impregnation technique in different geometries of the cidra vegetable matrix with orange solution
}

\begin{abstract}
The study of the composition, microstructure and properties of the structural food matrix is the main step for the elaboration of new products, in this case the matrix engineering uses the technique of vacuum impregnation to introduce into the food matrix, solutions that contain components to enrich it, allowing the elaboration of functional foods. The objective of this research was to evaluate the gain of soluble solids in citron of different geometries, through the technique of vacuum impregnation with an orange solution at $21^{\circ} \mathrm{Brix}$. The cidra was prepared in geometric shapes (parallelepipeds, sheets, cylinders, cubes and half spheres), and the solution was prepared from orange juice with the addition of sucrose up to $21^{\circ}$ Brix. The obtained results showed greater gain of soluble solids in the cylinders $(10.2 \pm 0.100)$ and lower gain in the half spheres $(7.8 \pm 0.152)$. In all the geometries there was a gain of soluble solids, however the cylinders were the most suitable structure for the process with the orange solution at $21^{\circ} \mathrm{Brix}$, since it managed to enrich the vegetable matrix with greater effectiveness.
\end{abstract}

Keywords: matrix engineering, vacuum impregnation, structural matrix, soluble solids
Volume 2 Issue 3 - 2017

Luisa Fernanda Herrera Dejesús,' Clara

María Mejía Doria, ${ }^{2}$ Luz Stella García-Alzate'

'University of Quindío, Colombia

${ }^{2}$ National University Sede Manizales, Colombia

\section{Correspondence: Clara María Mejía Dori, 2National}

University Sede Manizales, Colombia,

Email cmmejia@uniquindio.edu.co

Received:December 06, 2017 | Published:December 15, 2017

\section{Introduction}

Currently, new alternatives for healthy eating are being sought through the use of matrix engineering that studies the structural composition of foods to generate changes that improve their functional properties; Foods such as fruits and vegetables have in their microstructure pores that penetrate the tissues and are usually full of air, by immersing them in a solution and making vacuum, it is possible to remove part of the gases found in the pores and introduce them into said solution. ${ }^{1}$ This technique of matrix engineering is called vacuum impregnation (IV); therefore, as the solution may contain flavors, vitamins or bioactive compounds it is possible to achieve innovative and nutritious products. ${ }^{2}$ On the other hand, cidra, Sechium edule is a complete food because it contains carbohydrates, amino acids, proteins, minerals such as calcium, iron and phosphorus, vitamins A, $\mathrm{B}$ and $\mathrm{C}$, among other components. The composition of citron gives it important beneficial effects on health. Because of its high fibre content it is a good food for digestion and water is used as a diuretic in slimming treatments, urine retention or diabetes. ${ }^{3}$ However, despite the beneficial properties and their easy access and cultivation, their consumption, especially in Colombia, is not very recurrent. ${ }^{4}$ Taking into account the above, the objective of this research was to use the technique of vacuum impregnation to enrich the plant matrix of cidra by evaluating different geometries, using a solution based on orange and sucrose.

\section{Materials and methods}

Conditioning of the plant material: The fruits of cidra and orange were collected, with similar characteristics of size, texture and without apparent damage, were washed with 500ppm sodium hypochlorite solution according to the minimum requirements of Codex Alimentarius for fresh fruits and vegetables. ${ }^{5}$ Preparation of the vegetal material: The fresh fruits of cidra were peeled and cut into the geometries of cubes $(10 \mathrm{~mm}$ per side), sheets $(0.5 \mathrm{~mm}$ high and $14 \mathrm{~mm}$ per side and side), cylinders ( $0.5 \mathrm{~mm}$ diameter and $40 \mathrm{~mm}$ long), parallelepipeds $(0.5 \mathrm{~mm}$ wide, $0.5 \mathrm{~mm}$ high and $40 \mathrm{~mm}$ long $)$ and half spheres $(18 \mathrm{~mm}$ diameter and $10 \mathrm{~mm}$ depth). Regarding the orange, a solution with sucrose at $2^{\circ}$ Brix was prepared. Physicochemical characterization of cidra and orange: parameters of ${ }^{\circ} \mathrm{Brix}$ (AOAC 932.12), water activity (aw) AOAC 978.18, humidity percentage (AOAC 934.06), $\mathrm{pH}$ (AOAC 981.12), percentage of titratable acidity (AOAC) were evaluated. 942.15), percentage of ash, content of $\mathrm{Mg}, \mathrm{Na}, \mathrm{Ca}, \mathrm{K}$ (AOAC 985.35) and phosphorus (AOAC 995.11). Vacuum impregnation (IV): Vacuum impregnation was carried out in a conventional pressure cooker adapted to a manometer and a vacuum pump. The pressures used were 16 in $\mathrm{Hg}$ and impregnations were performed for a total time of half an hour, in which vacuum was applied for 5 minutes, and the next 5 minutes was removed, leaving it at rest, and so on until the total time was completed. Statistical analysis: The study of the significance of the different effects and their possible interactions was performed by analysis of variance (ANOVA) using the Turkey method (HSD), with a level of significance $(\alpha)$ of 0.05 , with the statistical package Statgraphics Centurion XV (Version 15.2.05).

\section{Results and discussion}

The physicochemical characterization of cidra and orange in fresh is shown in (Table 1). The physicochemical parameters evaluated determine the effectiveness of process of impregnation of the different geometries of cidra in the orange solutions. Figure 1 shows the values and behavior of the physicochemical parameter of ${ }^{\circ}$ Brix in the cidra in the orange solution at $21^{\circ}$ Brix. According to the results of (Table $1)$, it is observed that the physicochemical parameters that prevail in the orange juice are percentage of acidity, $\mathrm{pH}$, soluble solids, and 
minerals such as $\mathrm{Mg}, \mathrm{Na}$ and $\mathrm{K}$, which increase the nutritional value of the citron matrix to be incorporated into it. The results agree with the values reported by Morales among other authors for cidra. ${ }^{6}$ And for the orange they were similar to those reported among other authors by Toledo. ${ }^{7}$ The ANOVA presented statistically significant differences between the geometries ( $p$-value $\leq 0,05$ ). Taking into account the ${ }^{\circ}$ Brix of the cidra in fresh state $(5,1 \pm 0.100)$ and when comparing them with those presented in the geometric shapes evaluated (Figure 1), it was observed that after the IV there was gain of soluble solids. Similar results were reported in three geometries of cidra with blackberry solutions at $25^{\circ}$ Brix, showing an increase in soluble solids between 15,0 and $20,0^{\circ}$ Brix; parallelepipeds a greater increase. ${ }^{8}$ In another study made of cidra slices and cubes with three formulations of passion fruit: A ( $100 \%$ pulp), B (50\% pulp/water) and C (25\% pulp/ water), there was also evidence of gain in soluble solids 14,0 and $8,0^{\circ}$ Brix, respectively, with the sheets obtaining the highest gain. ${ }^{9}$ On the other hand, in this study, the cylinders presented the highest gain of soluble solids, obtaining $10,2 \pm 0,100 .^{10}$

Table I Physicochemical characterization of cidra (Sechium edule (Jacq.) Swartz) and orange (Citrus $\mathrm{x}$ sinensis (L.) Osbeck)

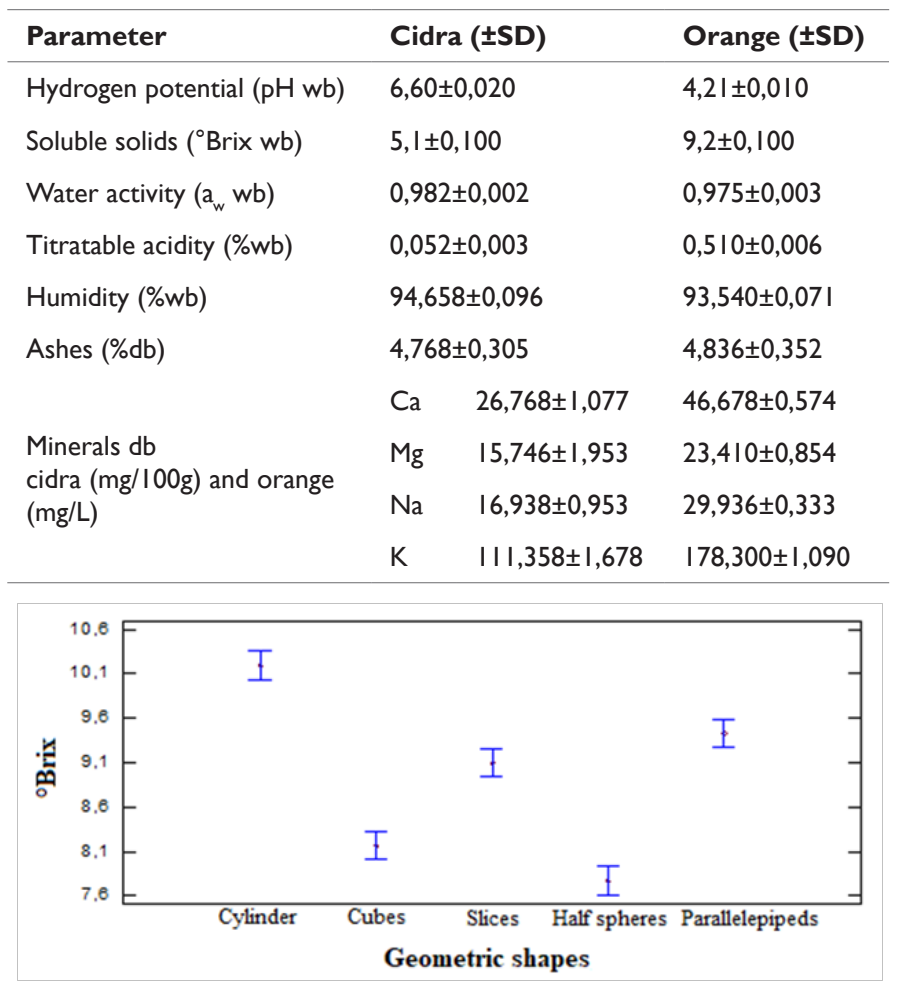

Figure I ${ }^{\circ}$ Brix of geometric shapes after of the vacuum impregnation with of solution of orange.

\section{Conclusion}

The technique of vacuum impregnation allows the gain of soluble solids, wich are present in solution impregnation (solutions of orange), and the geometric shape in cylinders was the most suitable structure for this process with the orange solution at $21^{\circ} \mathrm{Brix}$, improving the properties of the cidra matrix.

\section{Acknowledgements}

To the University of Quindío, to the Chemistry Program, to the New Products Design Laboratory.

\section{Conflict of interest}

The author declares no conflict of interest.

\section{References}

1. José Miguel Aguilera. Gastronomic Engineering. Santiago of Chile. Chile: 2010

2. Jorge Ferratto, María Cristina Mondino. Production, consumption and marketing of vegetables the world. Agromensajes. 2008. p. 1-3.

3. Rafael Humberto Villamizar, Yeison Rubio, David Torres. Formulation of cidra-based sauce (Sechium edule) with the addition of Moringa oleifera. Colombian Agronomy. 2016;34(1):1288-1291.

4. María EB. Technological development and functional appraisal of apple appetizers and mandarin juice. Antioxidant effect in obese children and probiotic effect against Helicobacter pylori infection in children. Spain: Polytechnic University of Valencia; 2012.

5. Official methods of analysis. Association of official analytical chemists Washington. 16th ed. USA: AOAC; 1996.

6. Valentina M, Cristian G. Formulation of a citron-based drink (Sechium edule (Jacq.). Swartz) enriched with calcium and flavored with lulo (Solanum quitoense var Castilla). Colombia. University of Quindio; 2016

7. Vera Adelina Toledo. Development of orange segments stabilized by heat treatment. University of the Americas Puebla; 2013.

8. Gladys EG, Alba LDC, Clara MDD. Impregnation of pieces of cidra Sechium edule with solutions of blackberry Rubus glaucus. Colombian Agronomy. 2016;34(1):598-601.

9. Clara MMD, Alba LDC, Luz Stella GA, et al. Physicochemical characterization of citron geometries (Sechium edule (Jacq) Sw). Vacuum impregnated with passion fruit. Colombian Agronomy. 2016;34(1):12111214.

10. Pedro F. Modeling of vacuum osmotic dehydration of foods. J Food Eng. 1994;22(1-4):313-328. 